\title{
INTRAPARENCHYMAL CHOROID PLEXUS PAPILLOMA- A CASE REPORT AND LITERATURE REVIEW
}

\author{
Jini Lonappan Valooran ${ }^{1}$, Anand T. P2, Noushad A3 , Joy Augustine ${ }^{4}$ \\ ${ }^{1}$ Assistant Professor, Department of Pathology, MCH, Thrissur. \\ ${ }^{2}$ Assistant Professor, Department of Forensic Medicine, MCH, Thrissur. \\ ${ }^{3}$ Senior Resident, Department of Pathology, MCH, Thrissur. \\ ${ }^{4}$ Professor, Department of Pathology, MCH, Thrissur.
}

ABSTRACT

\section{BACKGROUND}

Choroid plexus papilloma (CPP) is a rare, slow growing benign tumour of childhood with neuroectodermal origin. Their usual location is ventricle and associated with signs and symptoms of increased intracranial pressure and obstructive hydrocephalus. Rarely CPP can be intraparenchymal. Sudden deaths have been reported, but are very unusual. Here, we present a case of a 24year-old male brought for medicolegal autopsy examination on grounds of sudden unexplained death. An autopsy examination showed oedema of brain and an irregular, firm, nodular mass deep inside the white matter of left occipital lobe. Histopathology and Immunohistochemistry (IHC) confirmed the diagnosis of a choroid plexus papilloma.

\section{KEYWORDS}

Choroid Plexus Papilloma (CPP), Intraparenchymal, Adult, Sudden Death.

HOW TO CITE THIS ARTICLE: Valooran JL, Anand TP, Noushad A, et al. Intraparenchymal choroid plexus papilloma- A case report and literature review. J. Evolution Med. Dent. Sci. 2017;6(14):1153-1155, DOI: 10.14260/Jemds/2017/249

\section{BACKGROUND}

Choroid plexus papillomas are rare, accounting for less than $1 \%$ of all intracranial tumours in adults. They are relatively more common in childhood and constitute 1.5 to $4 \%$ of intracranial tumours.[1] They are neuroectodermal in origin, usually located in the ventricle and is composed of multiple papillary fronds mounted on a well-vascularised connective tissue stroma very similar in structure to the normal choroid plexus. Grossly, they may appear as reddish cauliflower like growths, which often become heavily calcified. ${ }^{22]}$ CPPs are not malignant; however, malignant evolution may occur, with an incidence of $10-30 \%$. In a recent series by McEvoy et al, the five-year survival rate was $100 \%$.[3] Exceptional cases of unusual locations like intraparenchymal, suprasellar region and spinal epidural are on record. To the best of our knowledge, only three cases of intraparenchymal CPP have been reported. Here, we describe a rare case of intraparenchymal CPP. Our case has an unusual location and unique histopathological features.

\section{Case Report}

A 24-year-old moderately built and nourished male was brought for medico-legal autopsy examination on ground of sudden death. He was known to complain of headache quite often. Autopsy examination showed brain oedema with an irregular firm nodular swelling measuring $8 \times 6 \times 3 \mathrm{~cm}$ deep inside the white matter of left occipital lobe near the gangliocapsular region with surrounding area filled with clear fluid (Figure 1). Ventricles were free with smooth inner wall. Other organs were within normal limits.

Financial or Other, Competing Interest: None.

Submission 08-01-2017, Peer Review 31-01-2017,

Acceptance 07-02-2017, Published 16-02-2017.

Corresponding Author:

Dr. Jini Lonappan Valooran,

\#VII/2A, 228B,

Poovani, Kolazhy,

Thrissur-680010.

E-mail: jinivalooran77@gmail.com

DOI: $10.14260 /$ jemds $/ 2017 / 249$

\section{(c) (i) $\$$}

\section{Gross Findings}

Irregular, firm, nodular grey white growth measuring $8 \times 6 \times$ $3 \mathrm{~cm}$ with a grey white granular cut section. (Figure 2).

\section{Microscopy}

Section showed a neoplasm composed of cells arranged in papillary pattern and in sheets (Figure 3 and 4). Individual cells had round to oval neucleus and moderate eosinophilic cytoplasm. Mitotic figures were less than one per high power field. Focal areas of necrosis and calcification were noted. Focal blurring of papillary pattern, with sheet like arrangement and areas of necrosis suggested a tumour is high grade. The differential diagnosis included metastatic papillary neoplasm, papillary meningioma, atypical choroid plexus papilloma and papillary ependymoma. Immunohistochemistry (IHC) was done. Markers used were cytokeratin, Vimentin, S100, GFAP, Thyroglobulin, EMA and Ki67. Cytokeratin, Vimentin and S100 showed strong positivity (Figure 5 to 9). Thyroglobulin EMA and GFAP were negative. Ki67 showed very low index. Immunohistochemistry confirmed our diagnosis of Choroiplexus papilloma.

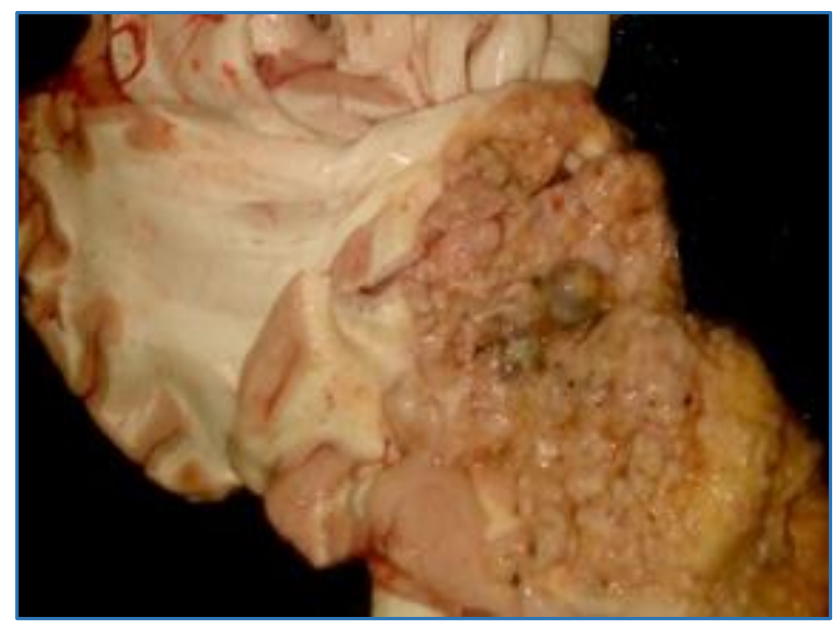

Figure 1. Gross Appearance of the Choroid Plexus Papilloma 


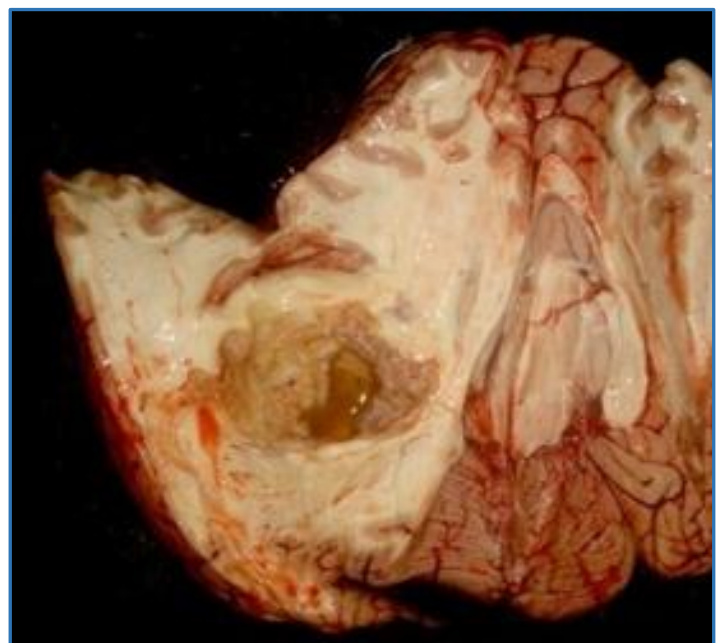

Figure 2. Gross Appearance of the Choroid Plexus Papilloma

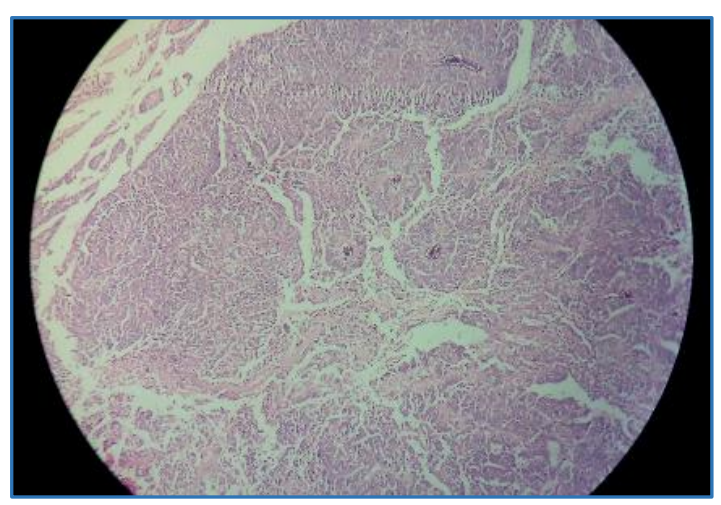

Figure 3. Scanner view of the Choroid Plexus Papilloma showing Papillary Areas (H \& E Low power view)

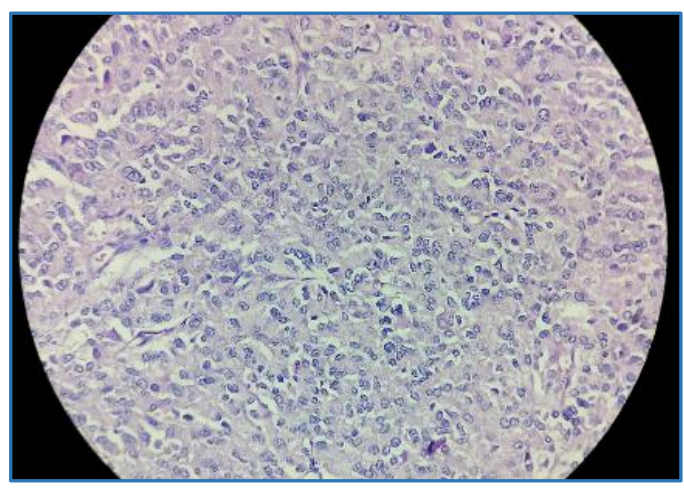

Figure 4. Microscopic Appearance of the Choroid Plexus Papilloma-(H\&E High power view)

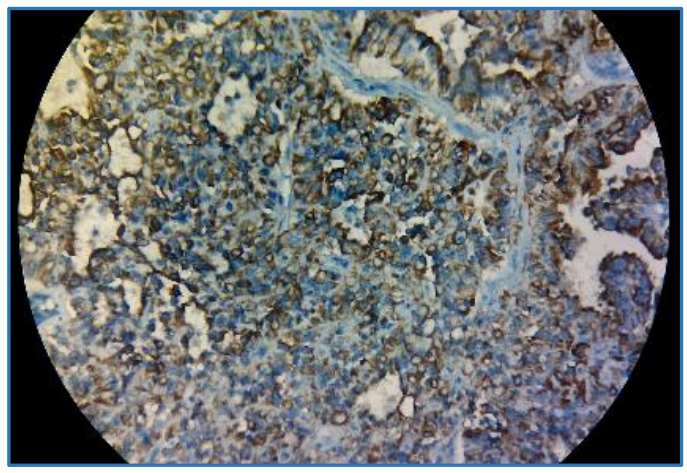

Figure 5. CPP with Expression of Cytokeratin

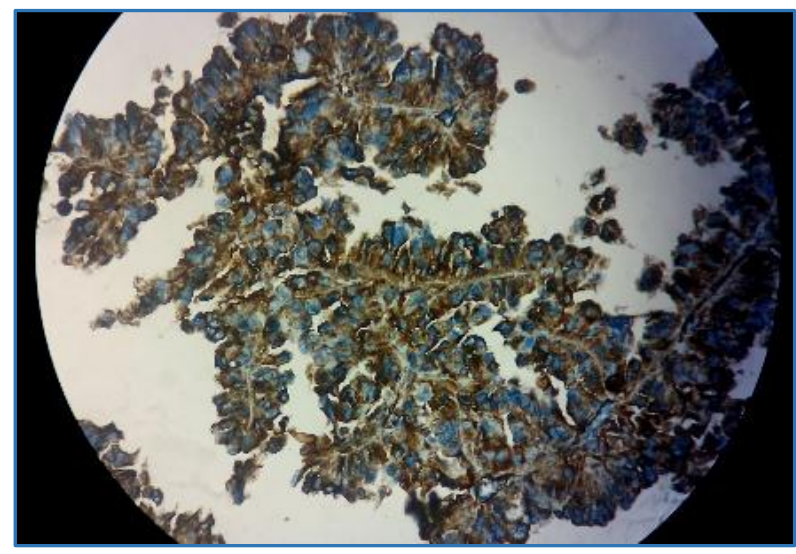

Figure 6. CPP with Expression of Vimentin

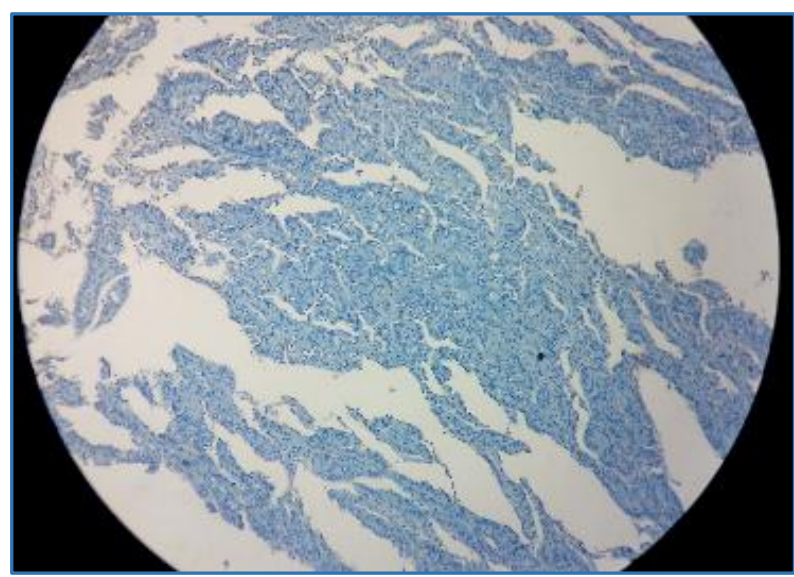

Figure 7. EMA done which is Negative

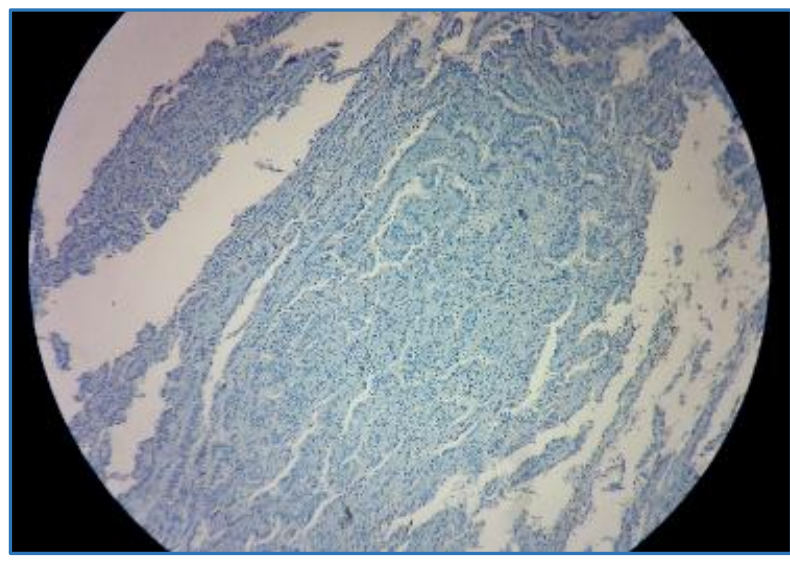

Figure 8. GFAP done which is Negative

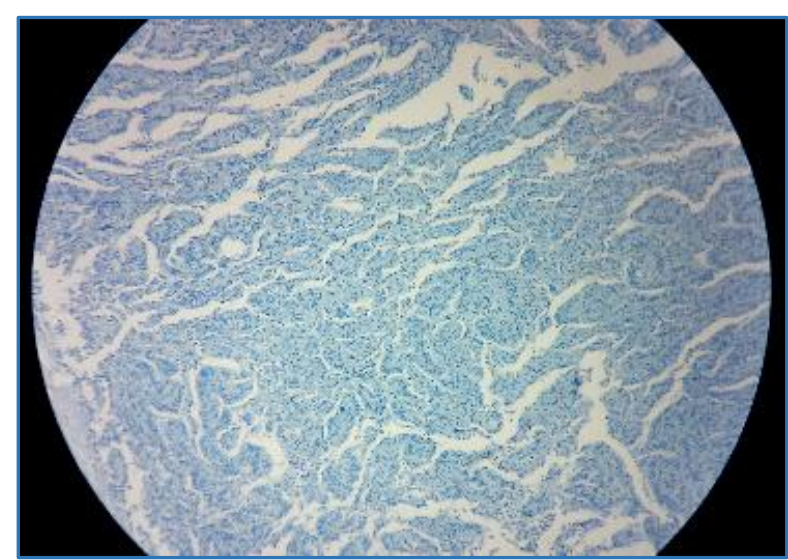

Figure 9. Thyroglobulin done- Negative 


\section{DISCUSSION}

Choroid plexus tumours are rare. Among these, papillomas are far more common than carcinomas. They usually arise from the ventricles. In adults the origin is far more common in lateral ventricle. About $20-40 \%$ of all choroid plexus tumours in children are carcinomas.[4] Carcinomas are rare in adults. CP angle tumours in the fourth ventricle has a tendency to grow through the Foramen of Luschka into the $\mathrm{CP}$ angle.[5] The usual duration of symptoms is reported to be about 1 month.[3] There has been case reports of sudden death where tumour involved the third ventricle and caused acute ventricular obstruction.[6] Grossly choroid plexus tumours are generally well-circumscribed brownish red cauliflower like masses. Malignant ones are invasive appearing haemorrhagic or necrotic. Histologically, there is a delicate connective tissue frond covered by a single layer of cuboid epithelium. The papilloma resembles normal choroid plexus but the cells are more crowded and elongated. The carcinoma is more cellular and shows features of anaplasia.

Rarely these tumours can undergo mucinous degeneration, melanisation, tubular glandular architecture or osseous and cartilaginous metaplasia.[7] In adults, most choroid plexus papillomas are heterogenous, secondary to cystic degeneration and or calcification. Treatment depends on a number of factors including the size, location, type and grade of the tumour as well as the age and health of the patient. Surgery may be the only treatment required if the tumour can be completely removed.

Our case is unique due to intraparenchymal location, and its variation in histology including blurring of papillary pattern with sheet like arrangement of cells, pleomorphism of cells, high cellularity and areas of necrosis which made diagnosis difficult. To the best of our knowledge, only 3 cases of intraparenchymal choroid plexus papillomas have been reported earlier. Among the reported cases one was in temporal lobe with hydrocephalus, $(8,9)$ another one was in right parietal mass resulting in intractable seizure reported by Masaaki et al in 2011,[10] and $3^{\text {rd }}$ case was in medial aspect of the left temporal lobe.[11] Our case is probably the first CPP to be reported in the occipital lobe.

\section{CONCLUSION}

Intraparenchymal CPPs are very rare. Differing from the usual bland pattern in CPP, blurring of papillary pattern with sheet like arrangement, high cellularity, nuclear pleomorphism and areas of necrosis though rare do occur.

\section{REFERENCES}

[1] Erman T, Gocer AL, Erdogan S, et al. Choroid plexus papilloma of bilateral lateral ventricle. Acta Neurochir (Wein) 2003;145(2):139-43.

[2] Lantos PL. The Nervous System. James O'D McGee, Isaacson PG, Wright NA. Oxford text book of pathology. Vol 2. Oxford university press 1992:1890.

[3] McEvoy AW, Harding BN, Phipps KP, et al. Management of choroid plexus tumors in children: 20 years experience at a single neurosurgery centre. Pediatr Neurosurgery 2000;32(4):192-9.

[4] Tomiyama A, Nakayama H, Aoki K, et al. Solitary metastasis of renal cell carcinoma to the third ventricular choroid plexus with rapid clinical manifestation by intratumoral hemorrhage. Neurol India 2008;56(2):179-81.

[5] Janisch W, Staneczec W. Primary tumors of the choroid plexus. Frequency, localization and age. Zentralbl Allg Pathol 1989;135(3):235-40.

[6] Gradin WC, Taylon C, Fruin AH. Choroid plexus papilloma of the third ventricle: case report and review of the literature. Neurosurgery 1983;12(2):217-20.

[7] Kleihues P, Cavenee WK. Tumors of the nervous system, international agency for research on cancer. Paris 1997.

[8] McCall T, Binning M, Blumenthal DT, et al. Variations of disseminated choroid plexus papilloma: 2 case reports and a review of the literature. Surg Neurol 2006;66(1):62-7.

[9] Jagielski J, Zabek M, Wierzba-Bobrowicz T, et al. Disseminating histologically benign multiple papilloma of the choroid plexus: case report. Folia Neuropathol 2001;39(3):209-13.

[10] Imai M, Tominaga J, Matsumae M. Choroid plexus papilloma originating from the cerebrum parenchyma. Surg Neurol Int 2011;2:151.

[11] Hung CC, Hsiao IH, Chen CC, et al. Intraparenchymal choroid plexus papilloma: a case report and literature review. JSM Neurosurg Spine 2014;2(6):1047. 